\title{
Arremessar por cima do ombro e a distância percorrida pelo implemento
}

CDD. 20.ed. 152.3

\begin{tabular}{|c|c|}
\hline $\begin{array}{l}\text { Samuel BENTO DA SILVA* } \\
\text { Guanis de Barros VILELA JUNIOR }{ }^{* *} \\
\text { Rute Estanislava TOLOKA* }\end{array}$ & $\begin{array}{l}\text { *Universidade Metodis- } \\
\text { ta de Piracicaba. } \\
{ }^{*} \text { U n n i v e r s i d a de } \\
\text { Estadual de Ponta } \\
\text { Grossa. }\end{array}$ \\
\hline
\end{tabular}

Samuel BENTO DA SILVA*

Rute Estanislava TOLOKA*
Universidade Metodis-

* * Universidade

\section{Resumo}

A habilidade de arremessar por cima do ombro tem sido bastante estudada, observando-se a velocidade do implemento, porém enquanto muitas tarefas têm como objetivo arremessar o mais longe possivel, a distância percorrida pelo objeto ainda não tem sido investigada. 0 objetivo deste estudo foi verificar se existe relação entre o estágio de desenvolvimento motor nesta habilidade e a distância percorrida pelo implemento e observar diferenças entre os gêneros masculino e feminino; 50 crianças, com idade entre 7-8 anos, de ambos os gêneros, procedentes de Piracicaba - SP foram analisadas enquanto arremessavam uma bola de tênis de campo, o mais longe possível. Cada criança realizou três arremessos intercalados e foi filmada com duas câmeras mini DV, tanto em vista lateral quanto posterior, enquanto arremessava. 0 nivel de desenvolvimento das crianças foi classificado, utilizando-se uma sequência de desenvolvimento e a distância percorrida pela bola foi registrada. Foi encontrada correlação significativa entre o nivel do desenvolvimento e a distância atingida. Diferenças entre os gêneros foram observadas: os meninos encontravam-se em niveis desenvolvimentais mais avançados em todas as ações e alcançaram maiores distâncias. Assim, o nivel de desenvolvimento desta habilidade mostrou-se importante para o alcance de seu objetivo (arremessar mais longe). Sugerese que o nível de habilidade é influenciado pelo meio ambiente e que oportunidades de movimento devem ser providenciadas para auxiliar o desenvolvimento integral da criança.

Unitermos: Desenvolvimento motor; Arremessar; Distância; Educação física.

\section{Introdução}

Estudos sobre o desenvolvimento de habilidades motoras têm sido realizados com diferentes enfoques e vários estudos investigaram a relação do desenvolvimento motor e a maturação do sistema nervoso central, descriçóes de mudanças observáveis no comportamento motor, análises do processo no qual o desenvolvimento motor ocorre e sobre o porquê desta ocorrência, conforme apontaram GESELL (1980), Clark e Whitall (1989), Roberton e Halverson (1984) e THELEN e UlRich (1991), dentre outros.

Vários estudos foram realizados tentando identificar uma série de estados estáveis (níveis de desenvolvimento) que ocorrem no padrão espaço-temporal de movimentos infantis, durante a aquisiçāo de habilidades motoras, como mostraram LANGENDORFER e ROBERTON (2002).

Entre os estudos que descreveram estes níveis estão o de Roberton (1977) e Roberton e HaLVERSON
(1984) que observando a habilidade de arremessar por cima do ombro, propuseram um padrão de movimento esperado para as diferentes faixas etárias, observando cinco componentes da tarefa, com níveis desenvolvimentais específicos para cada um, sendo que tais achados foram considerados válidos para estudos nos dias atuais, de acordo com RunNION, ROBERTON e LANGENDORFER (2003).

Estes estudos forneceram subsídios para várias pesquisas, dentre elas as que observaram a relação destes níveis com diferentes componentes da tarefa ou restriçōes ambientais, como pode ser visto em Roberton (1987), Barela e Barela (1997), RoBERTON e KonczaK (2001), Runion, Roberton e LANGENDORFER (2003), JACKSON (2006).

Diferenças entre os gêneros também têm sido percebidas nesta habilidade. HaLVERSON, ROBERTON 
e LANGENDORFER (1982), ROBERTON e KONCZAK, (2001), LANGENDORFER e ROBERTON (2002), RoBINSON (2006), JACKSON (2006) e LORSON (2006) notaram que os meninos apresentaram níveis mais avançados de desenvolvimento e maior velocidade da bola ou da execução do movimento que as meninas.

Procurando verificar se esta diferença poderia ser atribuída às oportunidades de prática, RuNION, RoBERTON e LANGENDORFER (2003) compararam duas gerações diferentes e em ambas os meninos apresentaram níveis de desenvolvimento mais avançados que as meninas, atingindo maiores velocidades com a bola, embora as meninas da segunda geração, possivelmente tiveram mais oportunidades de prática, que as outras; concluíram que as diferenças entre os gêneros ainda permanecem e precisam ser melhor investigadas.

Sendo uma habilidade importante para diferentes modalidades esportivas, o arremesso por cima do ombro tem sido estudado também no contexto do "baseball". Diferenças entre características cinemáticas de jogadores desta modalidade esportiva, habilidosos ou não, têm sido investigadas, relacionando-as com mecanismos de controle central do movimento, tais como o tipo de instrução recebida ou o tempo para soltar a bola, que podem afetar a velocidade máxima que ela atingirá ou o ajuste da posição dos dedos para produzir diferentes direções na bola; mecanismos de coordenação dos movimentos de diferentes segmentos

\section{Metodologia}

Participaram desse estudo 50 crianças, sendo 21 meninos e 29 meninas, entre sete e oito anos, cursando a segunda série do ensino fundamental, em uma Escola Municipal de Ensino Fundamental, na cidade de Piracicaba- SP. Todos os responsáveis pelas crianças assinaram o termo de consentimento livre e esclarecido. O estudo foi aprovado pelo Conselho de Ética em Pesquisa da Universidade onde o estudo foi realizado, com parecer $\mathrm{n}^{\circ}$. 82/04.

As atividades foram realizadas dentro de uma quadra coberta; a criança foi posicionada na linha de saída do arremesso onde recebia a instrução para arremessar a bola por cima do ombro o mais longe possível, após escutar o sinal sonoro. As demais crianças esperavam sua vez em uma fila, na lateral da desta zona. Cada criança realizou três arremessos alternados de arremesso, que foram gravadas com duas câmeras filmadoras, Sony, mini-DV, DCR- 30 (tipo NTSC), tanto em vista lateral quanto posterior. As duas filmadoras estavam fixadas corporais também têm sido estudados, como pode ser visto em Van den TillaAR e EtTema (2003), WatTs, Pessoto e Hore (2004), Jegede, Watts, Stitt e Hore (2005), Grezios, Gissis, Sotiropoulos, Nikolaidis E Souglis (2006), Gray, Watts, Debicki e Hore (2006) e Hirashima, Kudo, Watarai e OHtsuki (2006).

A observação destas características cinemáticas é utilizada para observar as técnicas de movimento empregados, buscando-se obter melhores resultados no jogo, conforme mostraram JORRIS, WAN MUYEN, Van Ingen Schenau e Kemper (1985), Hore e Watts (2005), Hore, Debicki e Watts (2005), para movimentos de "baseball" ou VAN DEN TillaAR e EтTемa (2003) em atividades de "handball".

No entanto, não foi ainda estabelecida a relação entre o nível de habilidade motora de arremessar por cima do ombro e a distância percorrida pelo objeto, o que no caso de algumas tarefas, tais como a de arremessos de peso ou lançamento de martelo ou disco, em provas de Atletismo, é muito importante, já que nestes casos o alvo da tarefa é arremessar o mais longe possível.

Assim, este estudo teve como objetivo levantar subsídios para esta discussão, investigando a relação entre o nível de habilidade motora demonstrado nos diferentes componentes da ação e a distância percorrida pelo implemento arremessado, bem como observando se há diferença entre os gêneros masculino e feminino.

em tripés e dispostas, uma na lateral do setor em que as crianças realizaram os movimentos, numa distância de 4,40 m e a outra atrás do executante, numa distância de 5,90 m, conforme FIGURA 1.

As imagens adquiridas foram transferidas para um computador notebook, com uma placa de aquisição de imagens da Pinnacle Studio, com "software" para tratamento de imagens Movie Box 9.0. A seleção da sequência de quadros que continham as imagens do início ao final do movimento foi feita manualmente, considerando-se como primeiro quadro o primeiro movimento após o sinal sonoro e como último aquele em que o braço utilizado para o arremesso retornava a posição inicial.

Para a classificação dos níveis desenvolvimentais foram seguidas as instruçóes de ROBERTON e HALVERSON (1984) e ROBERTON e KONCZAK (2001), sendo consideradas seis ações corporais: $\mathrm{OP}=$ Oscilação Preparatória do braço para trás; $A U$ = Ação do Úmero; AA = Ação do Antebraço, AT = Ação do Tronco; AP 
= Ação dos Pés e CP = Comprimento das Passada, conforme ilustrado no QUADRO 1.

A distância horizontal percorrida pelo implemento arremessado foi aferida com uma trena Starret de $50 \mathrm{~m}$ por duas pessoas que estavam nas proximidades do local no momento de execução do arremesso. A distância percorrida foi definida entre o ponto zero, fixado no solo, na posição de saída do arremesso e o local de primeiro contato da bola com o solo.
O tratamento estatístico utilizou o cálculo do coeficiente de Spearman, com nível de significância de $1 \%$, conforme proposto por AyREs (2003), para verificar a correlação entre a distância arremessada e o nível de desenvolvimento em cada componente da ação, nos três arremessos. Foi feita a análise da distribuição dos dados através do cálculo de média, desvio padrão e mediana para comparação dos resultados entre os gêneros.

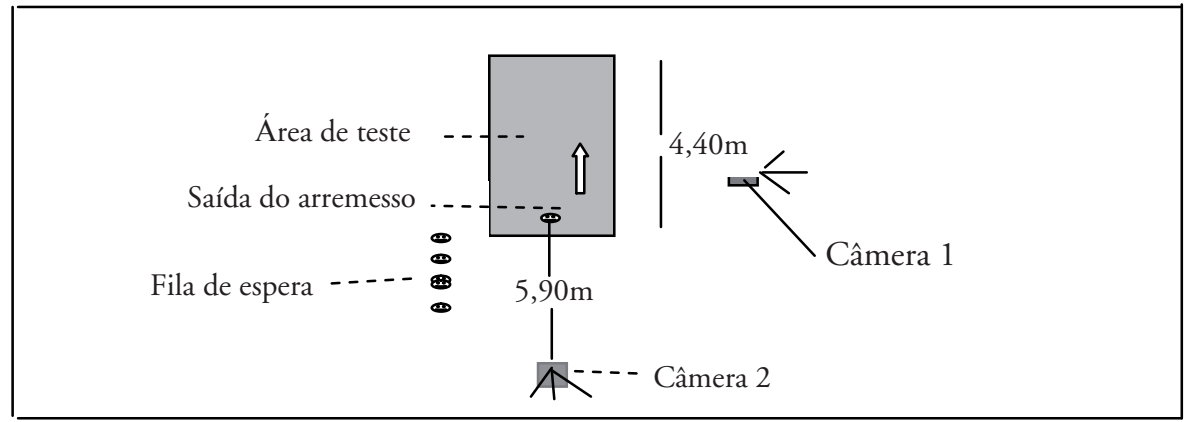

FIGURA 1 - Croqui da posição de câmeras e crianças para o arremesso.

QUADRO 1-Níveis desenvolvimentais por componentes da ação. (Adaptado de Roberton \& HaLverson, 1984 e ROBERTON \& KONCZAK, 2001).

\begin{tabular}{|c|c|c|c|c|}
\hline $\begin{array}{l}\text { Componente } \\
\text { da ação }\end{array}$ & $\begin{array}{c}\text { Nível de } \\
\text { desenvolvimento } 1\end{array}$ & $\begin{array}{c}\text { Nível de } \\
\text { desenvolvimento } 2\end{array}$ & $\begin{array}{c}\text { Nível de } \\
\text { desenvolvimento } 3\end{array}$ & $\begin{array}{c}\text { Nível de } \\
\text { desenvolvimento } 4\end{array}$ \\
\hline $\begin{array}{l}\text { Oscilação prepara- } \\
\text { tória do braço para } \\
\text { trás }\end{array}$ & Não há oscilação. & $\begin{array}{l}\text { Há uma pequena osci- } \\
\text { lação e flexão de coto- } \\
\text { velo e úmero. }\end{array}$ & $\begin{array}{l}\text { Balanço circular para } \\
\text { trás e para cima. }\end{array}$ & $\begin{array}{l}\text { Balanço circular para } \\
\text { trás e para baixo. }\end{array}$ \\
\hline Ação do úmero & $\begin{array}{l}\text { Permane oblíquo em } \\
\text { relação ao tronco. }\end{array}$ & $\begin{array}{l}\text { Ainda está fora da linha do } \\
\text { corpo, mas já faz um mo- } \\
\text { vimento independente. }\end{array}$ & $\begin{array}{l}\text { Alinha-se em relação } \\
\text { ao tronco e a bola. }\end{array}$ & - \\
\hline $\begin{array}{l}\text { Ação do } \\
\text { ante-braço }\end{array}$ & $\begin{array}{l}\text { Se move conforme a } \\
\text { bola, acompanha o } \\
\text { movimento do objeto } \\
\text { na mão. }\end{array}$ & $\begin{array}{l}\text { Parece estar parado, } \\
\text { junto com a bola, atrás } \\
\text { da criança. }\end{array}$ & $\begin{array}{l}\text { Está atrasado em re- } \\
\text { lação ao úmero. }\end{array}$ & - \\
\hline Ação do tronco & Sem ação do tronco. & $\begin{array}{l}\text { Rotação da parte } \\
\text { superior mantendo a } \\
\text { pélvis bloqueada, ou } \\
\text { rotação do tronco em } \\
\text { bloco. }\end{array}$ & $\begin{array}{l}\text { A pélvis faz um mo- } \\
\text { vimento mais rápido } \\
\text { que a coluna, assim } \\
\text { essa chega atrasada } \\
\text { para aumentar a ve- } \\
\text { locidade. }\end{array}$ & - \\
\hline Ação dos pés & Sem ação dos pés. & $\begin{array}{l}\text { O pé que se move para } \\
\text { frente é o que está do } \\
\text { mesmo lado do braço } \\
\text { de arremesso. }\end{array}$ & $\begin{array}{l}\text { O pé de apoio se } \\
\text { move para frente } \\
\text { mas ainda é pouco e } \\
\text { às vezes se move para } \\
\text { a lateral. }\end{array}$ & $\begin{array}{l}\text { Pé de apoio faz oposição } \\
\text { ao braço de arremesso. }\end{array}$ \\
\hline $\begin{array}{l}\text { Comprimento da } \\
\text { passada }\end{array}$ & Sem passada. & $\begin{array}{l}\text { Pequeno afastamento dos } \\
\text { membros superiores. }\end{array}$ & $\begin{array}{l}\text { Longo afastamento dos } \\
\text { membros inferiores. }\end{array}$ & - \\
\hline
\end{tabular}




\section{Resultados}

O nível de habilidade motora das crianças estava assim distribuído: na primeira e no segundo arremesso, 14 crianças apresentaram o nível mais avançado (3 ou 4) em todos os componentes da ação, no terceiro arremesso esse número foi de 13 crianças. Cinco crianças apresentaram nível 1 em pelo menos um dos níveis analisados, nos três arremessos.

A maioria das crianças não atingiu o nível mais avançado em todos os componentes. A porcentagem de crianças em cada nível de desenvolvimento, ou seja, nível 1,2 e 3 , em cada ação, foi respectivamente: $\mathrm{AU}=5,2 \%, 61,5 \%$ e $33,3 \%$; $\mathrm{AA}=5,2 \%$, $61,5 \%$ e $33,3 \%$; AT $=3,7 \%, 51,1 \%$ e $45,2 \%$; CP $=5,9 \%, 53,3 \%$ e $40,7 \%$. Nas ações com quatro níveis, os resultados foram: $\mathrm{OP}=5,2 \%, 40,7 \%, 0 \%$ e $54,1 \%$; $\mathrm{AP}=5,9 \%, 53,3 \%, 0 \%$ e $40,7 \%$.

Em relação às distâncias, a média entre todos os arremessos foi de $13,35 \mathrm{~m}$, com desvio padrão de $5,8 \mathrm{~m}$ e moda de $12,15 \mathrm{~m}$.

Houve correlação estatisticamente significante, considerando-se o coeficiente de spearman, para $\mathrm{p}$ $<0,01$, entre o nível da habilidade motora de arremessar por cima do ombro e a distância atingida em todos os componentes da ação, em todos os arremessos, exceto na fase de oscilação preparatória do braço para o arremesso. Os valores encontrados são apresentados na TABELA 1.

A análise intra-grupo, mostra que a maior média individual de distância foi de $24,51 \mathrm{~m}$ sendo acompanhada de níveis mais altos de desenvolvimento em todas as açōes e a menor foi $4,82 \mathrm{~m}$ que obteve nível 1 para todas as ações em todos arremessos.

Analisando as médias das distâncias do grupo em cada arremesso observa-se que no primeiro arremesso a média foi de $12,73 \mathrm{~m}$ sendo que 17 crianças arremessaram a distâncias superiores a média e destas 13 foram classificadas no nível 3 e quatro no nível $2 \mathrm{em}$ todas as ações; 28 crianças não atingiram a distância média do grupo, das quais uma criança estava no nível 3, 18 estavam em níveis 1 e 2 em todas as açōes, cinco apresentaram nível 3 nas açōes dos membros superiores e quatro nas ações dos membros inferiores.

No segundo arremesso, 20 crianças arremessaram mais do que a distância média que foi de $13,85 \mathrm{~m}$, entre elas 13 apresentaram nível 3 na maioria das ações; 25 crianças não atingiram a distância média sendo que destas 22 apresentaram nível 1 e $2 \mathrm{em}$ todas as ações. Uma criança apesar de estar no nível 3 na maioria das ações, esteve abaixo da média de distância. No terceiro arremesso, a distância média foi de $13,50 \mathrm{~m}$ e 15 crianças atingiram ou ultrapassaram essa marca, entre elas, 12 apresentaram níveis mais altos em todas as ações e três exibiram nível 3 apenas nos membros inferiores. Outras 30 crianças não alcançaram a distância média e entre elas uma estava no nível 3 na maioria das ações e duas estavam nos níveis 1 ou 2 em todas as ações.

Observando-se separadamente os resultados entre meninos e meninas, verifica-se que os meninos atingiram níveis mais desenvolvidos em todos os componentes da ação. Como pode ser visto na TABELA 2, a distribuição dos níveis desenvolvimentais entre os gêneros foi diferente em todas as ações. Enquanto que a maioria dos meninos atingiu o nível mais avançado em todas as ações, a maioria das meninas apresentou níveis intermediários de desenvolvimento. Por exemplo, 93\% dos meninos exibiram nível 4 na ação preparatória dos braços, enquanto que apenas $32 \%$ das meninas obtiveram este classificação e $60 \%$ delas estavam no nível 3.

O componente da ação onde as meninas apresentaram menor nível de desenvolvimento foi o ante-braço, onde $12 \%$ delas ainda se encontravam no nível 1 e nenhuma atingiu o nível 3; porém, 78\% dos meninos atingiram nível 3 nesta ação e nenhum estava no nível 1. Entre as meninas ocorreram casos em que todos os componentes da ação ainda estavam no nível 1 , o que não aconteceu com os meninos.

A observação da distribuição dos dados sobre as distâncias arremessadas nos dois grupos, considerando-se os três arremessos, mostra que os meninos atingiram distâncias mais longas que as meninas, arremessando em média $18,80 \mathrm{~m}$, com um desvio padrão de 5,01 m e mediana de $20,58 \mathrm{~m}$, enquanto as meninas obtiveram a média de $9,93 \mathrm{~m}$, com desvio padrão de 2,83 m e mediana de $10,12 \mathrm{~m}$, conforme pode ser visto na FIGURA 2. Embora a menor distância registrada foi de um menino, ela ocorreu apenas uma vez, no primeiro arremesso por ele realizada; nos demais arremessos os valores atingidos por este menino foram de $22,18 \mathrm{~m}$ e 23 m. Desconsiderando-se este arremesso, o menor resultado masculino foi $6,95 \mathrm{~m}$. O valor mínimo atingido pelas meninas foi de $3,55 \mathrm{~m}$. As maiores distância obtidas foram $27,10 \mathrm{~m}$ para os meninos e $19,28 \mathrm{~m}$ para as meninas. 


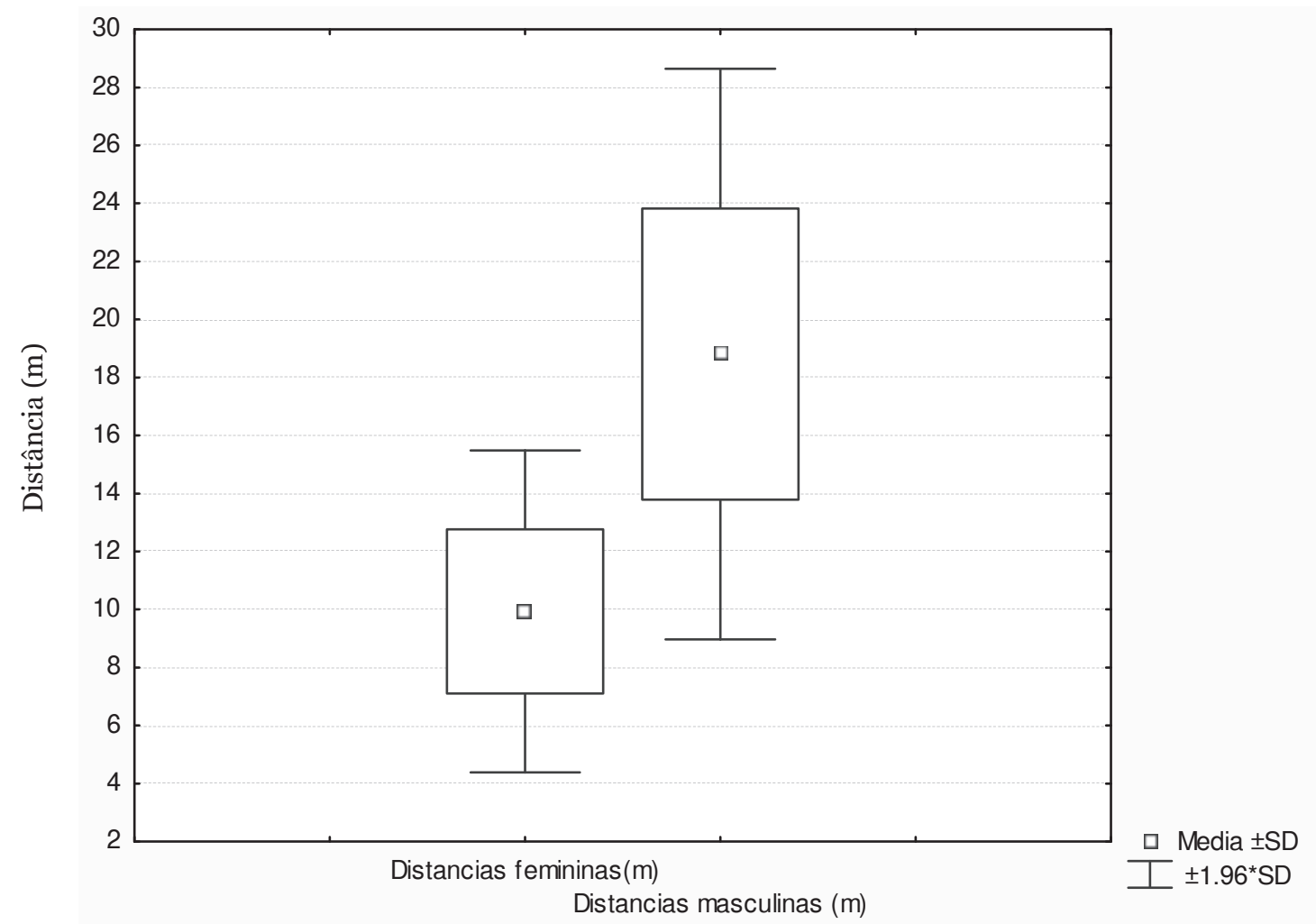

$\mathrm{SD}=$ desvio padrão.

FIGURA 2 -Box-Plot da distribuição das distâncias arremessadas, nos três arremessos.

TABELA 1 - Correlação entre o nível de desenvolvimento da habilidade motora e a distância atingida pelo implemento, nos três arremessos.

\begin{tabular}{|c|c|c|c|c|}
\hline Componente da ação & Primeiro arremesso & Segundo arremesso & Terceiro arremesso & \\
\hline Ação do úmero & $0,756^{*}$ & $0,746^{*}$ & $0,785^{*}$ & $\begin{array}{l}\text { correlaçao signilicativa } \\
\text { para } p<0,01 \text {; }\end{array}$ \\
\hline Ação do antebraço & $0,756^{*}$ & $0,746^{*}$ & $0,785^{*}$ & ${ }^{* *}$ correlação significati- \\
\hline Ação do tronco & $0,591^{*}$ & $0,717^{*}$ & $0,622^{*}$ & \\
\hline Ação dos pés & $0,544^{*}$ & $0,697^{*}$ & $0,665^{*}$ & \\
\hline Comprimento da passada & $0,544^{*}$ & $0,697^{*}$ & $0,665^{*}$ & \\
\hline Oscilação preparatória do braço para trás & $0,756^{*}$ & $0,746^{*}$ & $0,387^{* *}$ & \\
\hline
\end{tabular}


TABELA 2 - Frequência Absoluta (FA) e Frequência Relativa (FR) dos níveis de desenvolvimento observado nos componentes da ação, nos três arremessos, entre os diferentes gêneros.

\begin{tabular}{|c|c|c|c|c|c|}
\hline \multirow{2}{*}{ Componente da ação } & \multirow{2}{*}{$\begin{array}{c}\text { Nível de } \\
\text { desenvolvimento }\end{array}$} & \multicolumn{2}{|c|}{ Meninos } & \multicolumn{2}{|c|}{ Meninas } \\
\hline & & FA & FR (\%) & FA & FR (\%) \\
\hline \multirow{4}{*}{ Oscilação preparatória do braço para trás } & 4 & 54 & $93 \%$ & 28 & $32 \%$ \\
\hline & 3 & 0 & 0 & 52 & $60 \%$ \\
\hline & 2 & 9 & $7 \%$ & 7 & $8 \%$ \\
\hline & 1 & 0 & 0 & 0 & 0 \\
\hline \multirow{3}{*}{ Ação do úmero } & 3 & 49 & $78 \%$ & 5 & $6 \%$ \\
\hline & 2 & 14 & $22 \%$ & 75 & $86 \%$ \\
\hline & 1 & 0 & 0 & 7 & $8 \%$ \\
\hline \multirow{3}{*}{ Ação do tronco } & 3 & 48 & $76 \%$ & 5 & $6 \%$ \\
\hline & 2 & 15 & $24 \%$ & 75 & $86 \%$ \\
\hline & 1 & 0 & 0 & 7 & $8 \%$ \\
\hline \multirow{4}{*}{ Ação dos pés } & 4 & 48 & $76 \%$ & 0 & 0 \\
\hline & 3 & 0 & 0 & 25 & $29 \%$ \\
\hline & 2 & 15 & $24 \%$ & 57 & $65 \%$ \\
\hline & 1 & 0 & 0 & 5 & $6 \%$ \\
\hline \multirow{3}{*}{ Ação do antebraço } & 3 & 49 & $78 \%$ & 0 & 0 \\
\hline & 2 & 14 & $22 \%$ & 60 & $88 \%$ \\
\hline & 1 & 0 & 0 & 8 & $12 \%$ \\
\hline \multirow{3}{*}{ Comprimento da passada } & 3 & 48 & $76 \%$ & 19 & $22 \%$ \\
\hline & 2 & 15 & $24 \%$ & 60 & $69 \%$ \\
\hline & 1 & 0 & 0 & 8 & $9 \%$ \\
\hline
\end{tabular}

\section{Discussão}

A correlação estatisticamente significante encontrada entre a distância arremessada e o nível de desenvolvimento apresentado nas açóes corporais indica que quanto maior o nível de habilidade, maior a chance de o objeto ser lançado mais longe. Apenas na Oscilação Preparatória do Braço para trás, do último arremesso, esta correlação não foi significativa; isto pode ter ocorrido porque neste caso, a variabilidade no nível de desenvolvimento da ação diminuiu, sendo que $92 \%$ das crianças alcançaram o nível máximo, o que não ocorreu nos outros arremessos, em nenhum dos componentes analisados.

As correlações mais fortes relacionaram-se às açōes do braço e do ante-braço, isto pode ter ocorrido porque esta é uma atividade que aparentemente solicita mais dos membros superiores, porém verifica-se também que a ação do tronco e dos membros inferiores (Ação dos Pés e Comprimento da Passada) influencia na distância alcançada pelo implemento, como já havia proposto McGinNis (2002), quando afirmou que um arremesso realizado apenas com o impulso dado pelo membro superior não é eficiente para grandes distâncias ou altas velocidades, pois a força média exercida na bola é muito pequena em tempo relativamente curto. Este autor sugere que a melhor utilização dos diferentes segmentos do corpo pode trazer um aumento do tempo de aplicação de força sobre o implemento, aumentando o tempo de aceleração, consequentemente obtendo maior velocidade no momento do arremesso e levando o objeto a percorrer maior distância.

O tempo de aceleração e a velocidade no momento do arremesso não foram objetos deste estudo, contudo os dados aqui encontrados confirmam a hipótese em relação à distância; a relação da velocidade do implemento com o nível desenvolvimental, já havia sido anunciada com os achados de RoberTON e KONCZAK (2001), LORSON (2006), JACKSON 
(2006), inclusive entre os componentes da ação dos membros inferiores.

Observando-se as performances individuais verifica-se que as crianças que estavam nos níveis $1 \mathrm{e}$ 2 nas ações dos pés e no comprimento das passadas não atingiram o valor médio das distâncias. Notase também, que algumas crianças com níveis 3 e 4 nos outros segmentos mas com nível 1 ou 2 nos membros inferiores também tiveram dificuldade em atingir o valor médio, o que novamente aponta para a importância destes segmentos corporais na ação de arremessar. Desta forma, faz-se necessário que o movimento dos membros inferiores receba atenção nas tarefas de arremessar com as crianças, para que estas possam ter experiências que propiciem o desenvolvimento das ações dos pés e pernas, para aumentar a eficiência do movimento.

Observando-se o comportamento individual verifica-se que algumas crianças, mesmo estando em níveis mais avançados de desenvolvimento em todos os componentes da ação, não conseguiram atingir a distância média alcançada pelo grupo. Embora isto ocorreu em poucos casos, estes revelam que além do nível de habilidade bem desenvolvido outras variáveis podem estar influenciando no desempenho da tarefa e precisam ser averiguadas.

Para Bronfenkrenner (2005) o desenvolvimento de uma pessoa precisa ser observado considerando-se sua relação com o meio ambiente pois as propriedades da pessoa e do ambiente interagem para produzir constância e mudanças nas características pessoais através da vida e influenciam o desempenho de habilidades. Por isto o ambiente imediato onde a criança está inserida, pode influenciar na sua execução da tarefa. Inter-relaçõos pessoais, papeis sociais, atributos pessoais (condições de saúde e estado nutricional, entre outros) ou emoçôes vivenciadas podem desencadear, fortalecer ou enfraquecer as interações dependendo dos acontecimentos que envolvem a tarefa.

Talvez, as crianças que apresentaram níveis de desenvolvimento avançado mas arremessaram menores distâncias que a média do grupo, em sua interação com o meio foram influenciadas pelas outras crianças que estavam presentes no local, pelos pesquisadores, ou por características próprias que prejudicaram o desempenho frente a demanda ambiental de arremessar o mais longe possível. Assim novos estudos sobre a habilidade de arremessar e interaçôes ambientais poderiam trazer subsídios para auxiliar na compreensão do desenvolvimento desta habilidade.

Outro achado importante foi que a maioria das crianças não atingiu os níveis desenvolvimentais mais avançados, conforme proposto para esta faixa etária, por Roberton (1977) e Roberton e HaLVERSon (1984). Outros estudos no Brasil obtiveram dados semelhantes, tais como SANCHES (1992), BARELA e Barela (1997), Basso, Marques e Manoel (2005), Marques e Catenassi (2005), Barreto e Tremea (2006) que encontraram tanto crianças quanto adultos em níveis desenvolvimentais abaixo do previsto. Isto também pode ser observado nos estudos de Runion, Roberton e Langendorfer (2003), nos Estados Unidos onde a maioria das crianças encontravam-se no nível 2 na ação do úmero e do tronco. As explicações propostas por estes autores para a defasagem de desenvolvimento encontrada nas crianças relacionam-se a falta de oportunidades ou de instrução adequada para realização da tarefa.

A falta de oportunidades é um fator que merece atenção especial, frente ao desenvolvimento infantil. ARIÈs (1981) descreveu o cotidiano de uma criança do século XVII em paises ocidentais e mostrou que naquela época havia muitos espaços e tempo para o lazer e para os jogos de rua e praças; isto contribuía para a existência de ambientes propícios para o desenvolvimento de diferentes habilidades motoras.

Nos dias de hoje, como mostraram SIIVA, MARCELINO e TOLOCKA (2006), o grande fluxo de pessoas das áreas rurais para as áreas urbanas, o aumento do tráfico e da violência urbana e a má distribuição dos espaços antes utilizados para o lazer e agora ocupados por casas e indústrias, têm deixado as crianças com poucas opções para brincar. Além disto, a criança é sobrecarregada com inúmeros compromissos como se fossem adultos em miniatura. Todos estes fatores podem prejudicar o desenvolvimento de habilidades motoras, sendo necessário oportunizar vivências motoras a elas.

A falta de oportunidades também se relaciona às diferenças culturais, que propiciam diferentes experiências motoras. Em determinadas culturas algumas habilidades são mais valorizadas do que outras, o que se reflete nas brincadeiras infantis, nos brinquedos utilizados e nos esportes mais procurados. A diferença observada entre os gêneros neste estudo (as meninas estavam em níveis desenvolvimentais mais baixos e arremessaram menores distâncias) seria assim explicada. Embora a literatura apresente sugestōes como as de Halverson, Roberton e LANGENDORFER (1982), de que a diferença no nível de desenvolvimento estaria ligada a oportunidades de prática, isto ainda não foi completamente esclarecido, já que o estudo de RUNION, ROBERTON e LANGENDORFER (2003) apontou que mesmo com o aumento de prática na atividade de arremessar entre 
as meninas nas últimas décadas, elas ainda apresentam níveis desenvolvimentais menores que os meninos, embora tenham melhorado em relação às meninas de duas décadas anteriores.

Estes dados apontam para uma diferença que pode ser apenas parcialmente explicada pela oportunidade de prática. Outros fatores dentro de uma cultura podem estar interferindo na disposição destas crianças em praticar estas atividades. Ou seja, além de saber quantas horas estas crianças dedicaram na prática de habilidades de arremessar, seria necessário também observar como elas fizeram isto e a importância que estas crianças e as pessoas próximas a elas atribuíram a estas atividades. Seria interessante também verificar se recursos pessoais,

\section{Considerações finais}

O nível de desenvolvimento da habilidade motora básica de arremessar por cima do ombro mostrou-se importante para o desempenho da tarefa e alcance de seu objetivo (arremessar mais longe), embora em alguns casos, crianças que estavam nos níveis mais avançados em todos os componentes da ação não atingiram a distância média obtida pelo grupo, indicando que outros fatores também podem influenciar a distância do arremesso e precisam ser investigados.

Como em outros estudos, a maioria das crianças não atingiu o nível desenvolvimental tais como a composição corporal não estariam influenciando o nível de habilidade motora, como sugeriram Berleze, Haeffner e Valentini (2007).

É preciso observar ainda que nos últimos anos as crianças estão indo cada vez mais cedo para as escolas e lá permanecem cada vez mais tempo. Isto está associado às mudanças no meio ambiente que reduziram as possibilidades de prática de habilidades motoras, podendo trazer prejuízos ao desenvolvimento, o que aumenta a responsabilidade das escolas em relação ao desenvolvimento infantil, devendo estas oferecer experiências adequadas, combinando atividades culturalmente valorizadas com outras que propiciem oportunidade de prática das principais habilidades motoras básicas.

mais avançado em todos os componentes da ação e foram encontradas diferenças no desempenho entre os gêneros, sendo que os meninos estavam em níveis desenvolvimentais mais avançados e atingiram maiores distâncias com o implemento. A oportunidade de prática pode explicar parcialmente estes resultados, porém é necessária a realização de estudos que abordem a cultura onde a criança está inserida, de maneira mais ampla, observando como as atividades são realizadas e o significado delas para as crianças.

\begin{abstract}
Overarm throw and the distance traveled by the implement

Overarm throwing skill has been widely studied regarding the farthest throwing distance analysing the velocity of the implement; however the object's distance has not been investigated. The aim of this study was to verify if there is a relationship between the skill development and the distance reached by the object and to observe differences between genders. Fifty children, ages 7-8 years, both genders, from Piracicaba - SP, were analyzed while throwing a tennis ball as far as they could. Each child had three attempts. They were filmed with two mini DV cameras, from both side and rear views while performing. Children's movements were categorized using a developmental sequence and the distance covered by the ball was register. A positive correlation was found between the developmental level and the ball distance. Gender differences were observed; boys were in a more advanced levels in all actions and had farther throwing distances. So, developmental level of this skill was important to reach the task goal (throwing as far as possible). It is suggested that skill level is influenced by the environment and movement opportunities must be provided in order to help the children's global development.
\end{abstract}

UnITERMS: Motor development; Overarm throwing; Distance; Physical education. 


\section{Referências}

ARIÈS, P. História social da criança e da família. Rio de Janeiro: LTC, 1981.

AYRES, M. (Coord.). BioEstat 3.0: aplicaçôes estatísticas nas áreas das ciências biológicas e medicas. Belém: Sociedade Civil Mamirauá, 2003.

BARELA, A.M.F.; BARELA, J.A. Restrições ambientais no arremesso de ombro. Motriz, Rio Claro, v.3, n.2, p.65-72, 1997. BARRETO, L.; TREMEA, V.S. Análise dos padrôes fundamentais de movimento de crianças de 6 e 7 anos de idade e as contribuiçōos das aulas de educação física. Revista Brasileira de Educação Física e Esporte, São Paulo, v.20, p.321, 2006. Suplemento 5. Resumos do XI Congresso Ciências do Desporto e Educação Física dos Países de Língua Portuguesa, 2006. BASSO, L.; MARQUES, I.; MANOEL, E.J. Collective behaviour of components in overarm throwing pattern. Journal of Human Movement Studies, London, v.48, p.1-14, 2005.

BERLEZE, A.; HAEFFNER, L.S.B.; VALENTINI, N.C. Desempenho motor de crianças obesas: uma investigação do processo e produto de habilidades motoras fundamentais. Revista Brasileira de Cineantropometria e Desempenho Humano, Florianópolis, v.9, n.2, p.134-44, 2007.

BRONFENBRENNER, U. The bioecological theory of human development. In: (Ed.). Making human beings human: bioecological perspectives on human development. Thousand Oaks: Sage, 2005.

CLARK, J.E.; WHITALL, J. What is motor development? The lessons of the history. Quest, Champaign, v.41, p.183202, 1989.

GESELL, A. A criança dos 5 aos 10 anos. São Paulo: Martins Fontes, 1980.

GRAY, S.; WATTS, S.; DEBICKI, D.; HORE, J. Comparison of kinematics in skilled and unskilled arms of the same recreational baseball players. Journal of Sports Science, London, v.24, n.11, p.1183-94, 2006.

GREZIOS, A.K.; GISSIS, I.T; SOTIROPOULOS, A.A.; NIKOLAIDIS, D.V.; SOUGLIS, A.G. Muscle-contraction properties in overarm throwing movements. Strenght Conditioning Reserch, Champaign, v.20, n.1, p.117-23, 2006.

HALVERSON, L.E.; ROBERTON, M.A.; LANGENDORFER, S. Development of the overarm throw: movement and ball velocity changes by seventh grade. Research Quartely fior Exercise and Sport, Washington, v.53, n.198-205, 1982. HIRASHIMA, M.; KUDO, K.; WATARAI, K.; OHTSUKI, T. Control of 3D limb dynamics in unconstrained overarm throws of different speeds performed by skilled baseball players. Journal of Neurophysiology, Bethesda, v.97, n.1, p. 680-91, 2006.

HORE, J.; DEBICKI, D. B.; WATTS, S. Braking of elbow extension in fast overarm throws made by skilled and unskilled subjects. Experimental Brain Research, Berlin, v.164, n.3, p.365-75. 2005.

HORE, J.; WATTS, S. Timing finger opening in overarm throwing based on a spatial representation of hand path. Journal of Neurophsyiology, Bethesda, v.93, n.6, p.3189-99, 2005.

JACKSON, S.L. Effects of speed on overarm throwing: a dynamic systems perspective. In: AAHPERD National Convention and Exposition. Salt Lake City: AAHPERD, 2006.

JEGEDE, E.; WATTS, S.; STITT, L.; HORE, J. Timing of ball release in overarm throws affects ball speed in unskilled but not skilled individuals. Journal of Sports Science, London, v.23, n.8, p.805-16, 2005.

JORRIS, H.J.; VAN MUYEN, A.J.; VAN INGEN SCHENAU, G.J; KEMPER H.C. Force, velocity and energy flow during the overarm throw in female handball players. Journal of Biomechanics, New York, v.18, n.6, p.409-14, 1985. LANGENDORFER, S.J.; ROBERTON, M.A. Individual pathways in the development of forceful throwing. Research Quarterly for Exercise and Sport, Washington, v.73, n.3, p.245-56, 2002.

LORSON, K.M. Overarm throwing velocity of high-school-age boys and girls. In: AAHPERD National Convention and Exposition. Salt Lake City: AAHPERD, 2006.

McGINNIS, P.M. Biomecânica do esporte e exercício. Porto Alegre: Artmed, 2002.

MARQUES, I.; CATENASSI, F.Z. Restrições da tarefa e padrōes fundamentais de movimento: uma comparação entre o chutar e arremessar. Revista da Educação Física, Maringá, v.16, n.2, p.155-62, 2005.

ROBERTON, M.A. Stability of stage categorization across trials: Implications for the "stage theory" of overarm throw development. Journal of Human Movement Studies, London, v.3, p.49-59, 1977.

. Developmental level as a function of the immediate environment. In: CLARK, J.E.; HUMPHEY, J.H. (Orgs.) Advances in motor development research. New York: AMS Press, 1987.

ROBERTON, M.A; HALVERSON, L.E. Developing children: their changing movement: a guide for teachers. Philadelphia: Lea \& Febiger, 1984.

ROBERTON, M.A.; KONCZAK, J. Predcting children's overarm throw ball velocities from their developmental levels in throwing. Research Quarterly for Exercise and Sport, Washington, v.72, n.2, p.91-103, 2001. 
ROBINSON, L.E. Gender differences in developmental trajectories of overarm throwing in preschool children. In: AAHPERD National Convention and Exposition. Salt Lake City: AAHPERD, 2006.

RUNION, B.P.; ROBERTON, M.A.; LANGENDORFER, S.J. Forceful overarm throwing: a comparison of two cohorts measured 20 years apart. Research Quarterly for Exercise and Sport, Washington, v.74, n.3, p.324-30, 2003.

SANCHES, A.B. Estágio de desenvolvimento motor em estudantes universitários na habilidade básica de arremessar. Revista Brasileira de Ciência do Movimento, São Caetano do Sul, v.6, v.1, p.14-22, 1992.

SILVA, J.V.P.; MARCELINO, N.C.; TOLOCKA, R.E. Lazer infantil: direitos legais, transformações sociais implicaçōes ao crescimento e habilidades motoras. Licere, Belo Horizonte, v.9, n.1, p.81-96, 2006.

THELEN, E.; ULRICH, B. Hidden skill: a dynamic systems analysis of treadmill stepping during the first year. Monographs of the Society for Research in Child Development, Chicago, v.56, n.1, p.1-104, 1991.

VAN DEN TILLAAR, R.; ETTEMA, G. Instructions emphasizing velocity, accuracy, or both in performance and kinematics of overarm throwing by experienced team handball players. Perceptual and Motor Skills, Missoula, v.97, n.3, p.731-42, 2003.

WATTS, S.; PESSOTTO, I.; HORE, J. A simple rule for controlling overarm throws to different targets. Experimental Brain Research, Berlin, v.159, n.3, p.329-39, 2004.

ENDEREÇO

Samuel Bento da Silva R. Ernesto Furini, 241 - Campo Verde 13465-00o - Americana - SP - BRASIL e-mail: sa_trabalhos@yahoo.com.br
Recebido para publicação: 01/08/2007

1a. Revisão: 17/03/2008

2a. Revisão: 26/08/2008

3a. Revisão: 22/04/2009

Aceito: 20/07/2009 